\title{
CICLOS REPRESIVOS Y CONFLICTOS DE IDENTIDAD EN LAS CRÓNICAS DE ELENA PONIATOWSKA
}

\author{
OSWALDO ESTRADA \\ University of North Carolina at Chapel Hill
}

\begin{abstract}
Siempre he tenido preguntas y, hasta el día de hoy, no tengo una sola respuesta. Simplemente no tengo ninguna. Las busco en otra gente. En sus palabras, en sus actos, en las expresiones de sus rostros.
\end{abstract}

-Elena Poniatowska-1

Cada vez es más cierto que la globalización y el imperialismo ponen a prueba nuestras concepciones sobre la esencia de América Latina, su identidad en constante proceso de evolución y los andamios de los estudios latinoamericanos. $\mathrm{Y}$ es que todo a nuestro alrededor confirma aquello que Néstor García Canclini indicaba a finales del siglo pasado y a principios de éste: que la globalización, cuyo rasgo central es intensificar las interconexiones entre sociedades, o producir mayor intercambio transnacional, es un objeto omnipresente en diversos sectores translocalizados ${ }^{2}$. Debido a una serie de estrategias que transforman con rapidez no sólo a las macroempresas industriales sino también a las corporaciones financieras, al cine, la televisión, la música y la informática, el sujeto latinoamericano se ve afectado por inevitables procesos de asimilación y transculturación, interrelaciones regionales y diversos circuitos de comunicación entre América Latina, los Estados Unidos, Asia y Europa.

Frente a los «nuevos mestizajes» que se producen y reproducen en muchos espacios latinoamericanos, sin que sus habitantes parezcan incomodarse en lo más mínimo ${ }^{3}$, las crónicas de Elena Poniatowska nos obligan a redefinir y repensar las partes desperdigadas de la identidad mexicana, el actual impacto del colonialismo en las relaciones políticas de México, así como la índole, formación y permanencia de una cultura popular. Aunque vivimos en un mundo donde la hibridez toma el lugar del patrimonio nacional, las crónicas de Poniatowska sugieren que hay elementos culturales de la identidad mexicana que son inamovibles, precisamente porque ésta se sostiene en torno a la discriminación étnica y social, a la desigualdad económica, al mal gobierno y a la estructuración piramidal de una sociedad anclada en un pasado que no avanza hacia la democracia. Esta propuesta ratifica no sólo que la identidad cultural de una sociedad es el conjunto de obras, modos y estilos de vivir que permiten reconocer y aprehender una cultura a través de la historia ${ }^{4}$, sino que ésta, pese a sus cambios, mantiene ciertas particularidades con base en sus confrontaciones y diálogos con el presente y el pasado ${ }^{5}$. Gracias a este carácter orgánico de la identidad cultural, que funciona a manera de dialéctica viviente entre lo «uno» y lo «otro» (Aínsa, op. cit., pp. 39-44), Poniatowska expone con efectividad un lado marginal del patrimonio social mexicano que, aun cuando es silenciado por el poder o ignorado por los más privilegiados, forma parte esencial de la mexicanidad.

El análisis que aquí propongo presupone que la identidad cultural de América Latina en
Oswaldo Estrada

Profesor en la Universidad de North Carolina at Chapel Hill. Ha trabajado sobre la obra de Carmen Boullosa, Rosario Castellanos, y Manuel Scorza, así como en autores en los que se hace vivo el discurso disidente. Los recursos del lenguaje sufren su propia metamorfosis en la obra de Carlos Fuentes, Elena Poniatowska o Carlos Monsivais. Investigación que se inició en el estudio de Bernal Díaz del Castillo, La imaginación novelesca. Bernal Díaz del Castillo entre géneros y épocas. Participó en el último Congreso Trasatlántico con una ponencia sobre Elena Poniatowska.
1

Traduzco un fragmento de su relato autobiográfico: «A Question Mark Engraved on My Eyelids», en Margaret Sayers Peden (ed.) Mexican Writers on Writing, San Antonio, Texas, Trinity UP 2007, p. 107.

2

Nestor García Canclini, La globalización imaginada, Buenos Aires, Paidós, 2005, pp. 11-24.

3

Para un mejor análisis de los «mestizajes» contemporáneos que se han convertido en todo un campo de estudios dentro del imperialismo académico de los Estados Unidos, véase El error del acierto (contra ciertos dogmas latinoamericanistas) de Wilfrido H. Corral, (Quito, Paradiso Editores, 2006, pp.117-140).

4

Fernando Aínsa, Identidad cultural de Iberoamérica en su narrativa, Madrid, Gredos, 1986, p. 29.

5

Néstor García Canclini, Culturas híbridas. Estrategias para entrar y salir de la modernidad, México, Grijalbo, 2001, p. ix.

Ciclos represivos y conflictos de identidad en las crónicas de Elena Poniatowska

OSWALDO ESTRADA 
6 Todd Gitlin, "The Cant of Identity», in Daphne Patai \& Will H. Corral (eds.), Theory's Empire. An Anthology of Dissent New York, Columbia UP, 2005 p. 401; Jorge Larrain, Identity and Modernity in Latin America, Oxford, Polity, 2000, pp. 24-26.

7

Octavio Paz, Tiempo nublado, Barcelona, Seix-Barral, 1983, p. 161. Sobre el desarrollo de la crónica mexicana, desde la conquista hasta la era contemporánea, véase el trabajo de Carlos Monsiváis, "On the Chronicle in Mexico», en Ignacio Corona \& Beth E. Jörgensen (eds.), The Contemporary Mexican Chronicle. Theoretical Perspectives on the Liminal Genre, Albany, State U of New York P, 2002, pp. 26-44.

8

Anadeli Bencomo, Voces y voceros de la megalópolis. La crónica periodístico-literaria en México, Madrid, Iberoamericana / Vervuert, 2002, p. 48.

9

Susana Rotker, La invención de la crónica, México, Fondo de Cultura Económica/ Fundación para un Nuevo Periodismo lberoamericano, 2005, p. 17.

10

Linda Egan, Carlos Monsiváis. Culture and Chronicle in Contemporary Mexico, Tucson, U of Arizona P, 2001, p. 35; Sara Poot Herrera, «Las crónicas de Elena Poniatowska», Colmena 11 (1996), p. 17.

11

Elena Poniatowska, Todo empezó el domingo, México, Océano [1963], 1997, p. 128.

12

Elena Poniatowska, La noche de Tlatelolco, México, Era [1971], 2001 , p. 16.

13

Elena Poniatowska, Nada, nadie. Las voces del temblor, México, Era, 1988, p. 306.

14

Elena Poniatowska, Amanecer en el Zócalo, México, Planeta, 2007, p. 252.

Ciclos represivos y conflictos de identidad en las crónicas de Elena Poniatowska

OSWALDO ESTRADA gran medida se ha definido y seguirá definiéndose a través de su narrativa, extendiéndose con fluidez en el tiempo y el espacio del discurso escrito. En el caso particular de México, los textos de Poniatowska conservan no una esencia innata pero sí un proceso de construcción social, donde los individuos se autodefinen o se identifican con ciertas cualidades, revelan algunos aspectos materiales que los hacen pertenecer a una comunidad (marginal), siempre en presencia de otros, a semejanza o diferencia de otros, y en intercambio con otros $^{6}$. Lejos de imponerse ante el lector como un tedioso inventario cultural mexicano, sus crónicas -como en su tiempo y a su manera lo hicieron las de Bernal Díaz, Guillermo Prieto, Martín Luis Guzmán, Salvador Novo, y ahora las de Cristina Pacheco o las del culturólogo Carlos Monsiváis- ratifican las preguntas que de sí misma se hace la sociedad, con imágenes y metáforas que retratan e inventan el mundo social del cual provienen? ${ }^{7}$.

Aun cuando Elena Poniatowska sigue escalando la cumbre del cuento y la novela, con premios y reconocimientos que aplauden sus más recientes trabajos literarios, como La piel del cielo (Premio Alfaguara de novela 2001), Tlapalería (2003) y El tren pasa primero (Premio Internacional de novela Rómulo Gallegos 2007), sus crónicas urbanas problematizan el rostro de la identidad mexicana con un espíritu de denuncia social. Valiéndose del testimonio polifónico, la técnica del reportaje periodístico y gráfico, y una perspectiva ciudadana múltiple, la escritora fabrica un retrato hablado de su país con voces fragmentadas y conflictivas, que se enfrentan de manera complaciente o disidente, mientras toman conciencia de su realidad ${ }^{8}$. Ésta ha sido su trayectoria desde los reportajes reunidos en Todo empezó el domingo (1963), La noche de Tlatelolco (1971) y Fuerte es el silencio (1980), hasta los testimonios que forman parte de Nada nadie. Las voces del temblor (1988), Luz y luna, las lunitas (1994), y Amanecer en el Zócalo (2007). Aprovechando la naturaleza mixta del género cronístico y la posibilidad que éste presenta para "postular preguntas apasionantes acerca de la institución literaria y de la cultura»9, Poniatowska descubre un México de grupos marginales atrapados en un perenne ciclo de opresión. Hasta cierto punto, sus crónicas tienen algo en común con las de Carlos Monsiváis: le dan voz a una mitad del país que casi nunca aparece en las páginas oficiales de la historia ${ }^{10}$. Sólo que en los escritos de Poniatowska raras veces pasamos de la denuncia a la transformación, o del espacio mítico y/o melodramático de la cultura popular hacia la anhelada modernidad.

El escenario de fondo donde muchos de sus personajes periféricos se desenvuelven nos presenta a la ciudad de México entre los telones del parque de Chapultepec, La Villa de Guadalupe o La Lagunilla, Xochimilco, las azoteas, la Plaza Garibaldi, Tepito o La Calle de las Novias. A veces, el lenguaje que emplea Poniatowska captura literariamente el habla popular de los vendedores de gorditas, el de los trajineros y el de las «inditas» del Zócalo ${ }^{11}$. En otras ocasiones, sin embargo, el coro de voces habla por los jóvenes al frente de un Movimiento Estudiantil, aquellos que en La noche de Tlatelolco luchan ante la «represión»12 y denuncian a un "gobierno que monologa con el gobierno» (Ibíd., p. 38). Como sabemos, la versión final de este retrato urbano es la del silenciamiento y la indignación de un pueblo que en vano busca a los muertos de una matanza incomprensible, bajo el autoritarismo de Gustavo Díaz Ordaz, en 1968. Es ésta la misma imagen dolorosa que deambula hacia otras crónicas de su autoría, para reflejar a una sociedad que en 1985 todavía padece de «una profunda castración mental» ${ }^{13}$; aquella que en el año 2006 se reúne en el Zócalo con el rostro desencajado ante lo que parece ser un (nuevo) fraude electoral. Bien mirada, la multitud fronteriza, pisoteada y ninguneada que observamos en las crónicas reunidas en Fuerte es el silencio habla también por los desaparecidos y presos políticos, por las mujeres que se organizan para ayudar a los damnificados de los terremotos, o por los miles de mexicanos (provincianos, en su mayoría) que están dispuestos a dormir en el suelo, a resistir la lluvia y el granizo en apoyo de un candidato presidencial que es visto como el único camino a una democracia ilusoria.

Fiel a su consabido compromiso ético y social con México, «en un afán de abarcarlo en su forma más completa» (Poot Herrera, op. cit., p. 18), Poniatowska invade la conciencia ajena, defiende causas que otros consideran perdidas, y tiende a disminuir su presencia autorial a favor de una voz colectiva, proveniente de la cultura de masas. Moviéndose así, entre la creación literaria y el testimonio, entre la oralidad y la letra, entre los círculos de poder y los «mexicanos de escasa instrucción» que para la gente privilegiada «no tienen oficio ni beneficio y están al margen de todo» ${ }^{14}$, la cronista nos presenta a México como «un país de molinos,» pero 
«no de viento sino de nixtamal» ${ }^{15}$. Esta particularidad no sólo distingue a Poniatowska de otras escritoras mexicanas como vocera de aquellos que son borrados por el poder ${ }^{16}$, sino que le permite representar la conciencia nacional y traducir a su patria ${ }^{17}$. Desde esa postura, la cronista retrata al 68 mexicano como un espacio inseparable del tiempo prehispánico, donde la supervivencia de una cultura sólo es posible gracias a «la sangre pisoteada de cientos de estudiantes, hombres, mujeres, niños, soldados y ancianos» (Poniatowska, Tlatelolco, op. cit., p. 171). Años más tarde, la visión que Poniatowska nos entrega de los sismos del 85 será la de un México azotado no sólo por la naturaleza, el pánico y el horror ante la muerte, sino por el ejército y la policía que lo único que hacen es «estorbar» y «robar» como representantes de un gobierno «inepto y corrupto» (Poniatowska, Nada, nadie, op. cit., pp. 120, 307). Como si el tiempo pasara en vano, o en el mejor de los casos de manera circular, en la última elección presidencial (2006), la cronista expone una constancia problemática de su país: «¿es México una democracia? No, no lo es, nos cuentan cuentos. Cuando nacemos hacemos un pacto para toda la vida. Lo firmamos a ciegas hasta el día en que nos damos cuenta de que no hemos llegado a la democracia. México no llega nunca» (Poniatowska, Amanecer, op. cit., pp. 118-19).

Tal vez como respuesta implícita a los postulados con respecto a las culturas híbridas o los efectos de la globalización «circular» y «lateral» (García Canclini, op. cit., p. 12), o porque este fenómeno pocas veces beneficia a las zonas marginales, Poniatowska se aferra en pintarnos la fachada de un México inconforme, de constantes demostraciones públicas y atropellos políticos, víctima de innumerables catástrofes, gobernado con insensibilidad, presa del dolor y el sufrimiento de cientos de miles que son expulsados de la historia como si fueran nada o nadie ${ }^{18}$. Mientras Jean Franco observa cómo las nuevas migraciones culturales mezclan la alta cultura con lo más primitivo o autóctono, los medios masivos con la oralidad, los lenguajes en distintas fronteras y las clases sociales en ámbitos transnacionales ${ }^{19}$, Poniatowska registra en sus crónicas a un México de hondas diferencias sociales, de pobreza imperante y «relativa libertad,» pese a las Convenciones Nacionales Democráticas de 1994 o del 2006 ${ }^{20}$. Ante esta situación alarmante, y en total negación de los supuestos cambios hacia la democracia, no hace mucho la escritora pronunció a todo volumen:

José Clemente Orozco tuvo razón al alzar su mano llena de pinceles rojos y fustigar la corrupción, el influyentismo, el maltrato, la pobreza, el saqueo, la falta de educación en todos sus niveles, el racismo y el clasismo, las desigualdades económicas y sociales que divi-

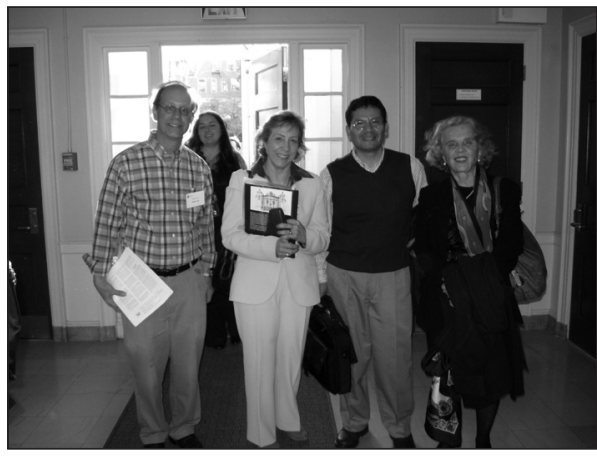
den al país y nos agobian. Hoy, en pleno 2006, 85 por ciento de los mexicanos ganan menos de cinco salarios mínimos... y para nuestra vergüenza hay quienes sobreviven con mucho menos, ya no se diga, los diez millones de indígenas que además han sido despojados de sus tierras. (Poniatowska, Amanecer, op. cit., p. 371)

Lo sorprendente de sus crónicas, empero, es que en ellas dialogan la indignación y la esperanza de una sociedad civil, que unida deja oír «el grito de Tenochtitlan, el grito que abarca más de quinientos años, el grito de los vencidos, el grito desgarrador de 1910 que mató a un millón de mexicanos, el grito de nuestros antepasados cuyos huesos palpitan bajo las baldosas» de la ciudad (Ibíd., p. 392).

A la luz de estos pronunciamientos, es innegable que en sus textos Poniatowska se aleja de todo lo abstracto y busca la inestabilidad oculta de su sociedad. Su discurso desestabiliza las nociones históricas del canon y plantea otros sistemas de valores, «para dar a conocer las condiciones de los desaparecidos políticos, que los hay en México, y de la gente más pobre: los campesinos que vienen en épocas de sequía a la ciudad, que llaman los golondrinos, y sus mujeres, las marías, que venden mimosa en la calle» ${ }^{21}$. Detrás de este reportaje puntual, en el que Monsiváis observa por ratos «intensidad prosística» y ciertos «vislumbres poéticos»22, es posible encontrar aquello que distingue a sus compañeros cronistas. Es decir: la representación de una realidad concreta, hecha de vivencias locales y nacionales; el juicio personal; la crítica social a través de una escena; el establecimiento de contrastes por medio de la caracterización certera de los personajes; los choques propios de una crisis; la inclusión sino de varios idiomas, de varios dialectos o registros; la persuasión por medio de detalles y un tono sarcástico; la atención en la cultura popular; la tendencia a otorgar la palabra a los otros; así como una mezcla de distintos géneros donde la autora jamás desaparece el referente ni se distancia
15

Rosa Beltrán, "Elena Poniatowska. Literatura y periodismo", Revista de la Universidad de México, 51 (2008), p. 8.

16

Elizabeth Coonrod Martínez, «Elena Poniatowska: Between the Lines of the Forgotten", Américas, $57: 2$ (2005), p. 48

17

Denise Dresser, «Elena Poniatowska: soldadera de lo nuestro", Revista de la Universidad de México, 39 (2007), p. 19

18

Claire Brewster, Responding to Crisis in Contemporary Mexico. The Polical Writings of Paz Fuentes, Monsiváis, and Poniatowska, Tucson, $\mathrm{U}$ of Arizona $\mathrm{P}$, 2005, pp. 103-110.

19

Vivian Schelling, «Popular Culture in Latin America», in The Cambridge Companion to Mo dern Latin American Culture, John King (ed.), Cambridge, Cambridge UP, 2004, p. 197.

20

Esteban Ascencio, Me lo dijo Elena Poniatowska. Su vida, obra y pasiones, contadas por ella misma..., México, Ediciones del Milenio, 1997, p. 56.

21

Rocío Oviedo Pérez de Tudela, «Palabra y tierra: entrevista a Elena Poniatowska», Anales de Literatura Hispanoamericana, 30 (2001), p. 342.

22

Michael K. Schuessler, Elenísima. Ingenio y figura de Elena Poniatowska, México, Diana, 2003, p. 314.

Ciclos represivos y conflictos de Poniatowska

OSWALDO ESTRADA identidad en las crónicas de Elena 


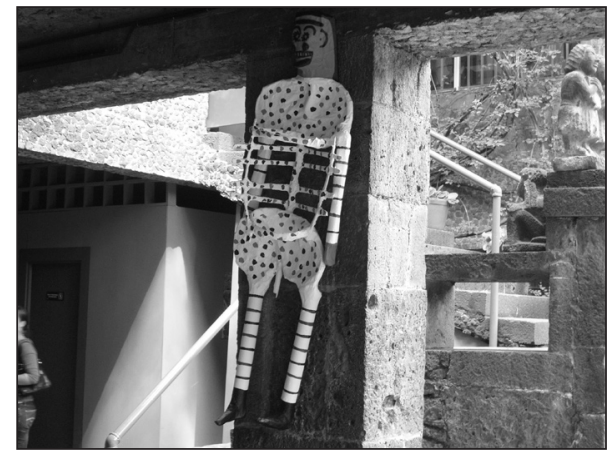

Jardín de la casa de Frida Kahlo.

23

Roger Bartra, La jaula de la melancolía. Identidad y metamorfosis del mexicano, México, Debolsillo, 2006, p. 24.

24

Bolívar Echeverría, Vuelta de siglo, México, Era, 2006, pp. 176-177.

25

Elena Poniatowska, Luz y luna. Las lunitas, México, Era, 1994 p. 26.

Ciclos represivos y conflictos de identidad en las crónicas de Elena Poniatowska

OSWALDO ESTRADA de aquello que escribe (Egan, op. cit., pp. 84, 92-93). Gracias a esta aproximación conocemos a Demetrio Vallejo como el héroe de los ferrocarrileros, aquel que pasa once años en la cárcel alimentándose únicamente de leche; comprendemos el presidencialismo en su auge, con la figura de Díaz Ordaz, el padre de la nación mexicana que infantiliza a todos sus habitantes; y recordamos la manifestación del silencio, la invasión militar de la UNAM, a las costureras del terremoto del 85, y a cientos de hombres y mujeres de todas las edades que hace dos años, bajo el liderazgo de Jesusa Rodríguez y Andrés Manuel López Obrador (AMLO), confrontaron a México $\mathrm{y}$ sus instituciones gubernamentales en un plantón masivo en el mismo centro histórico del Distrito Federal.

Si encajáramos su obra dentro de las teorizaciones de Roger Bartra con respecto a la identidad mexicana, encontraríamos, sin duda, que Poniatowska se mueve en el territorio de los fenómenos nacionales, donde es posible distinguir mitos, tipos y estereotipos, en una larga cadena de polaridades, "Occidente y Oriente, civilización y salvajismo, revolución e inmovilidad, ciudad y campo, obreros y campesinos, razón y emoción» ${ }^{23}$. Lo original de su prosa, sin embargo, es que el perfil de dominación, explotación y poder no se construye «a partir de las imágenes que la clase dominante se ha formado de la vida campesina y de la existencia obrera, del mundo rural y del ámbito urbano» (Ibíd., p. 16), sino desde el punto de vista del sujeto silenciado. Aquello que en un primer plano se presenta en la página impresa como mera nostalgia y melancolía, o como recuerdos borrosos en la memoria colectiva de un pueblo que oscila entre «lo que quiere hacer» y «lo que puede hacer» (Ibid., p. 101), pronto se convierte en un mural literario de la mexicanidad. Al igual que aquél compuesto por Octavio Paz, en $E l$ laberinto de la soledad, el mural identitario de Poniatowska también contiene diferentes escenas, «en cada una de las cuales las imágenes conceptuales se conectan entre sí y se invaden las unas a las otras» ${ }^{24}$.

En este lienzo cultural nos persuaden los vendedores ambulantes, los yerberos, el nevero, los zapateros, los hombres que entran y salen de las (casi inexistentes) pulquerías, o aquellos que caminan por las calles del centro donde «hierve un perol, humea un bote de tamales, un anafre o un sartén grande colmado de aceite,» ahí por donde todavía "pulula el pueblo taquero, torero, pozolero, empinarrefrescos $»^{25}$. Incluso cuando la globalización ha llegado a México, los escritos de Poniatowska reviven el perenne crujir de «las enchiladas, los tacos, las tostadas, las garnachas, el chorizo y la longaniza» (Id.). Nos llevan ahí donde las calles se pierden y quedan desamparadas, donde alguna vez vivió Jesusa Palancares, donde el aire, lejos de ser transparente, huele a ropa, axilas y frentes, a quesadillas de papa y flor de calabaza. Desde luego, esto ha hecho-hay que mencionarlo-que un crítico como Christopher Domínguez Michael tilde a Elena Poniatowska de «aristócrata populachera» que «se ufana de los mexicanismos que le enseñaron sus criadas indígenas y escribe sobre ellas, como sobre los estudiantes asesinados, los desaparecidos políticos, los damnificados del temblor, que, en fin, tiene, a los ojos de sus incondicionales, a sus Pobres esperando caridad a las puertas de su palacio» (Schuessler, op. cit., p. 308).

Lo que no debemos olvidar es que, en total reconocimiento de una «pluralidad o diversidad en la cultura» latinoamericana en general y mexicana en particular (Echeverría, op. cit., p. 196), Poniatowska nos transporta desde el mundo periférico de las colonias pobres, donde reina el espiritualismo, hasta las puertas de otro México que se afana en llegar a la modernidad, al de Perisur, por ejemplo, ese «centro comercial donde se agrupan 149 tiendas en torno a cuatro grandes almacenes: El Palacio de Hierro, El Puerto de Liverpool, París Londres y Sears,» donde se encuentran «vestidos, maquillajes, cremas, pelucas, detergentes y aparatos para adelgazar,» como un reflejo más de «nuestro agringamiento y una injuria al pueblo de México» (Poniatowska, Luz y luna, op. cit., pp. 115-116). Al cronicar éstos y otros extremos de la identidad mexicana, la escritora no tarda en sentenciar: «los latinoamericanos no nos hemos repuesto de la conquista a pesar de que los conquistadores arraigaron en nuestros países y de ellos nacimos. Todavía hoy padecemos las consecuencias de la brutal supresión de todas las tradiciones consideradas bárbaras» (Ibid., p. 133).

Sus retratos de la ciudad son convincentes porque definen la marginalidad en un mundo de confrontaciones cotidianas. Los chilangos habitan un Distrito Federal que «ha perdido su aire de campo», «hasta los gallos son citadinos y los guajolotes pavos de supermercado", 
«ya no hay campesinos ni rebozos, ni sombreros de paja», y en cambio abundan aquellos que «hablan inglés: 'okey', 'fuck you', 'shit', 'bye' y 'ciao' aunque sea en italiano" (Poniatowska, Todo empezó, op. cit., p. 14). Precisamente porque estos tipos sociales se desarrollan en contrate con otros, y para mostrar que existen muchos Méxicos dentro de un mismo ámbito nacional, el paisaje cultural que la escritora construye para nosotros incluye a sus mujeres ilustres -Pita Amor, Elena Garro, María Izquierdo y Rosario Castellanos; a sus escritores e intelectuales -Rulfo, Paz, Fuentes, Monsiváis; a sus activistas, como el Subcomandante Marcos o a los políticos, como AMLO. Independientemente de que estemos de acuerdo o no con sus posturas políticas, la pluma de Poniatowska nos ofrece en distintas ocasiones a un México que espera la democracia por enésima vez como si fuera por vez primera, y deja constancia, a principios del siglo XXI, de miles de mexicanos provenientes de los sectores más desprotegidos, aquellos que arman sus casitas de campaña en pleno Zócalo y cocinan a «flor de banqueta,» comparten su miseria y pobreza, al mismo tiempo que exigen justicia con la voz de la indignación: «México es nuestro por legítimo derecho, no somos huérfanos, somos mexicanos y hoy más que nunca México nos pertenece en esta gran fiesta de la resistencia» (Poniatowska, Amanecer, op. cit., p. 25).

Mientras los analistas teorizan sobre la política y la efectividad o el fracaso de distintas instituciones gubernamentales, una cronista como Poniatowska nos deja ver cómo estos organismos socio-políticos influyen en la interioridad de un pueblo marginado. Es más, su contemplación de la injusticia, la desigualdad y el sufrimiento del otro, le permite enmarcar «las problemáticas y desiguales relaciones de poder entre individuos y entre grupos sociales en la sociedad mexicana» $\mathrm{o}$, a un nivel más privado, las «relaciones desiguales entre patronas y sirvientas, el desarraigo y el miedo que experimenta la joven campesina al llegar a la capital en busca del trabajo, las deficientes leyes laborales, la explotación, el abuso y la enajenación» ${ }^{26}$. Poniatowska examina estas realidades desde una perspectiva analítica y al mismo tiempo cómplice, con intervenciones que se tornan autorreflexivas y autocríticas, en textos desafiantes, dedicados a narrar los silencios que gritan y piden justicia (Ibíd., pp. 417-424). Así es como sus crónicas rescatan personajes e instituciones que invariablemente contienen innegables marcadores

de aquello que podemos considerar como una mexicanidad multifacética, de variado origen étnico, histórico, social.

Volviendo al tema de la identidad cultural que hoy se distancia de una noción tradicional y se presenta como un fenómeno transcultural, cambiante, que oscila entre la autonomía y la pertenencia, o entre las similitudes y las diferencias, en general Jardín de la casa de Frida Kahlo.

podemos afirmar que existen ciertos factores que nos ayudan a delinearla dentro y fuera del ámbito latinoamericano, no tanto como un deseo o creencia sino como una realidad concreta. Aun cuando la identidad misma puede ser vista como un mito, o incluso si ésta se apoya en distintos mitos que circulan en el imaginario colectivo y propagan temores compartidos, anhelos comunitarios sobre un mundo mejor o la conciencia histórica de un pueblo ${ }^{27}$, toda identidad cultural apela a sus orígenes y se enorgullece de ellos; gira alrededor de ciertos momentos históricos importantes, ligados a situaciones de inestabilidad, amenazas y situaciones de crisis; es manipulable y se construye tomando en cuenta la alteridad ${ }^{28}$. Un breve repaso de las crónicas de Poniatowska confirma el desarrollo de una concepción cultural similar.

Si por un lado las viñetas de Todo empezó el domingo se presentan ante el lector como una serie de escenas costumbristas sobre los mexicanos de condición humilde ${ }^{29}$, sus siguientes colecciones de crónicas se centran en el delineamiento de grandes heridas nacionales. Me refiero, por supuesto, a la protesta y masacre estudiantil de 1968 (Tlatelolco); al registro de los desaparecidos, los que hacen huelga de hambre, o los que llevan una existencia precaria en la Colonia Rubén Jaramillo (Fuerte es el silencio); a los dos terremotos de 1985 (Nada, nadie); al levantamiento de los zapatistas en 1994, al mando del Subcomandante Marcos (diversas notas periodísticas) ${ }^{30}$; o a los cincuenta días del plantón del 2006, en que cientos de representantes de distintos estados mexicanos esperan darle fin a la política de corrupción que ha dominado al país por luengo tiempo (Amanecer). Lo más sobresaliente de estos momentos de crisis, magistralmente retratados por Poniatowska, es que retornan al lector a los orígenes de la cultura mexicana, porque es ahí donde permanecen intactas las preguntas irresueltas sobre la identidad cultural.
26

Beth E. Jörgensen, "Actos de atención: intersecciones en el pensamiento social de Weil Castellanos y Poniatowska», Revista Canadiense de Estudios Hispánicos, 31:3 (2007), pp. 414-417.

27

Enrique Florescano (ed.), Mitos mexicanos, México, Aguilar, 1995, pp. 9-10.

28

Herminio Núñez Villavicencio, «Sobre el concepto de identidad latinoamericana», Cuadernos Americanos, 124 (2008), pp. 184-195.

29

Beth E. Jörgensen, The Writing of Elena Poniatowska: Engaging Dialogues, Austin, $U$ of Texas P, 1994, p. 70

30

Claire Brewster recoge mucho de este material periodístico en su libro Responding to Crisis, prestando especial atención toda una diversidad de artículos en los que Poniatowska apoya abiertamente al líder zapatista.

Ciclos represivos y conflictos de identidad en las crónicas de Elena Poniatowska

OSWALDO ESTRADA 


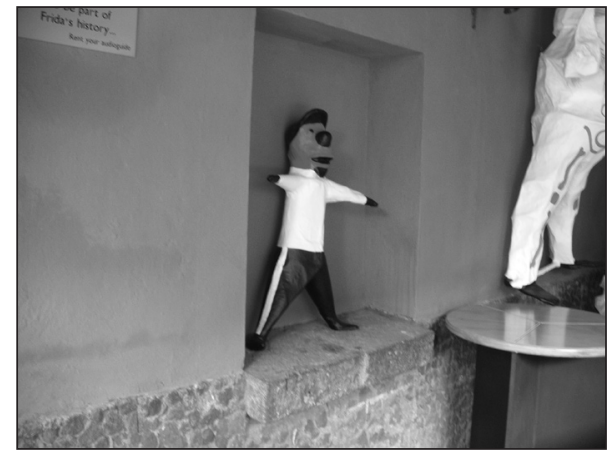

Jardín de la casa de Frida Kahlo.

31

Enrique Krauze, La presencia del pasado, México, Tusquets, 2005, pp. 23, 171-76, 342

\section{2}

Egan, op. cit., pp. 31-33; Beth $\mathrm{E}$. Jörgensen, «Matters of Fact: The Contemporary Mexican Chronicle and/as Nonfiction Narrative», en Ignacio Corona \& Beth E. Jörgensen (eds.), The Contemporary Mexican Chronicle. Theoretical Perspectives on the Liminal Genre, Albany, State $U$ of New York P, 2002, p. 79.

33

Margarita García Flores, «Entrevista a Elena Poniatowska», Revista de la Universidad de México, 30:7 (1976), p. 27.

34

Elena Poniatowska, «How I Started Writing Chronicles and Why I Never Stopped», en Ignacio Corona \& Beth E. Jörgensen (eds.), op. cit., p. 38.

Ciclos represivos y conflictos de identidad en las crónicas de Elena Poniatowska

OSWALDO ESTRADA
Del mismo modo en que La noche de Tlatelolco de 1968 se explica como otra «Noche triste» (Poniatowska, Tlatelolco, op. cit., p. 170), haciendo referencia a la de 1519 en que muchos españoles pierden la vida al escapar de los mexicas, el plantón del Zócalo en el 2006 es descrito por la cronista cual si fuera «un inmenso tianguis como el que le atribuyó Diego Rivera a la gran Tenochtitlan y pintó celestialmente» (Ibíd., p. 30). Esta presencia del pasado en el imaginario mexicano, que en cualquier momento puede revivir a los gobernantes prehispánicos, a los primeros conquistadores y frailes como a los padres fundadores de un México independiente, con tal de enjuiciar al presente ${ }^{31}$, permite que Poniatowska registre cómo a partir de la conquista México ha sido manejado por una sucesión de gobiernos hegemónicos que insisten «en marginar del espacio y las acciones ciudadanas a elementos de su propia realidad» (Bencomo, op. cit., p. 81). Si consideramos, además, que desde Bernal Díaz en adelante la crónica ha sido el género marginal que mejor documenta la inmediatez de las experiencias del desastre ${ }^{32}$, es lógico que Poniatowska se valga de ella (y de las fotografías que ilustran cada uno de sus textos cronísticos) para presentar la otra cara de México: «la fea, la convulsionada, la disidente» de una ciudad «que oficialmente se condensa gloriosa en las imágenes del Ángel de la Independencia, el Zócalo [y] la Catedral» (Bencomo, op. cit., p. 89).

Dicha revisión irónica del pasado aparece con frecuencia en los escritos de Poniatowska: al recordarnos, por ejemplo, que la matanza de Tlatelolco se realiza en La Plaza de las Tres Culturas, que sobre las ruinas prehispánicas fue construida en el siglo XVI la iglesia de Santiago de Tlatelolco, y que el párroco de ésta le cierra sus puertas a los manifestantes del 68 que son violentados ahí mismo (Poniatowska, Tlatelolco, op. cit., p. 173). Lo hace otra vez en el 85 , recalcando que la misma plaza «es un campo de batalla» para «familias incompletas» (Poniatowska, Nada, nadie, op. cit., p. 20), y que en México vuelve a tener sentido el Manuscrito Anónimo de Tlatelolco (1528), que reza:

En los caminos yacen dardos rotos; los cabellos están esparcidos. Destechadas están las casas, enrojecidos tienen sus muros. Gusanos pululan por calles y plazas, y están las paredes manchadas de sesos: Rojas están las aguas cual si las hubieran teñido, y si las bebemos, serán agua de salitre. Golpeábamos los muros de adobe en nuestra ansiedad y nos quedaba por herencia una red de agujeros. (Poniatowska, Nada, nadie, op. cit., p. 95)

Más de veinte años después de aquella catástrofe, la reflexión sobre el caos que ocasiona el plantón de dimensiones desbordantes dirige la atención de Poniatowska a un pasado prehispánico, para afirmar que en pleno siglo XXI México siente la cólera de Tláloc y Huitzilopochtli, «los dioses de la lluvia y de la guerra» que «a cada rato se rebelan y estallan coléricos en estelas, lápidas, piedras y pasadizos para demostrar que aún son ellos quienes mandan» (Poniatowska, Amanecer, op. cit., p. 54).

Es interesante que en una entrevista de 1976, Poniatowska se declare en desacuerdo con Octavio Paz, quien sostenía que la Plaza de las Tres Culturas era un lugar de perpetuo sacrificio debido a la herencia azteca que condenaba a México a una serie de matanzas ${ }^{33}$. El enunciado que rechaza una imagen cíclica de la historia mexicana nos sorprende no sólo porque en el año 2001 la escritora declare que México es moderno y prehispánico, horrible y fascinante, que besa y apuñala a la vez ${ }^{34}$, sino porque implícitamente, y tal vez sin que ella se lo haya propuesto, su obra cronística conserva el retrato de un México trágico atrapado en las telarañas de su historia, en un tiempo de dimensiones "carnavalescas» en todo el sentido bajtiniano, donde muchos son los condenados a vivir entre las voces de los muertos o entre exangües sobrevivientes, como si metafóricamente formaran parte de una ficción rulfiana. Tomemos como ejemplo el caso de Amanecer en el Zócalo, la crónica más reciente de Poniatowska que, de principio a fin, nos hace caminar sobre sus textos anteriores, sobre los renglones torcidos de la historia y sobre el espacio cultural de un pueblo marginado que aún espera ser reconocido por las autoridades.

La historia que ahí se presenta es la de otra conquista, ya no la del trono mexicano como en tiempos de Hernán Cortés y sus soldados, pero sí la de la búsqueda combatiente de la libertad, la del sueño de un México mejor, donde puede ser posible la democracia y un gobierno justo. El júbilo de los mexicanos que, al sentirse defraudados en las elecciones presidenciales del 2006, se lanzan a apoyar a su líder, es bastante parecido al de los muchachos 
del 68 que tocan las campanas de la Catedral y se sienten dueños de un Zócalo iluminado de esperanza. Si Cortés tuvo a la Malinche, AMLO también encuentra su brazo derecho en la persona de Jesusa Rodríguez, sin cuyo activismo político y tesón sobrenatural el plantón sería impensable. Por lo menos así lo imagina Elena Poniatowska, quien, al igual que Bernal Díaz, se entrega a la tarea de inmortalizar con sus letras un suceso histórico trascendental. Adoptando la postura favorita del soldado cronista, la del testigo de vista, Poniatowska compone un retrato hablado de una sociedad mexicana en pleno movimiento, con personajes mayores y menores que viven un espectáculo popular.

Como verdaderos participantes de un carnaval medieval en que se desintegran las reglas sociales y es posible la ilusión de comunidad, libertad, igualdad y abundancia ${ }^{35}$, durante cincuenta días los mexicanos del plantón se desentienden de «los términos oprimidos y opresores» (Poniatowska, Amanecer, op. cit., p. 38), gozan de un ambiente «donde las divisiones sociales pierden todo sentido» ante la tarea de supervivencia (Id.), y cambian la rutina diaria: «Gente que ni por equivocación se dirigía la palabra ahora se habla. Rompieron su ritmo y su estilo de vida. Caminan de otro modo porque han descubierto una manera totalmente distinta de vivir la calle» (Ibíd., pp. 30-31). En la crónica Poniatowska recalca «el apoyo de la colectividad» (Ibíd., p. 37); registra una resistencia alegre por parte de la gente que escucha «conciertos de música clásica, boleros, música country, ranchera, el rap, el reggaetón, rock pesado» (Ibid., p. 47); pinta a la gente muy pobre desprendiéndose de «unos pesitos» a favor del plantón (Ibíd., p. 86); y se admira de la convivencia pacífica de «limpias espiritistas y misas católicas, funciones de video, insultos, recitales, campeonatos de futbol, concursos de belleza y hasta burócratas en patines» (Ibíd., p. 101). Como si el tiempo diera vueltas hacia atrás para seguir hacia adelante, la fiesta popular que aquí se celebra con un sentido de solidaridad y liberación temporal, con miras al cambio y la renovación, pero con hostilidad hacia todo lo inmortalizado y completo (Bakhtin, op. cit., p. 9), también tiene su antecedente en $\mathrm{Nada}$, nadie, donde la escritora anota el compañerismo de los mexicanos en movimientos de corsi e recorsi:

Diego, estoy sola.

Frida Kahlo en su diario, 1955.
Diego, ya no estoy sola.

Frida Kahlo, 3 días después.

Mundo estoy solo. México, 19 de septiembre de 1985

Mundo, ya no estoy solo.

México 21 de septiembre de 1985. (Poniatows-

ka, Nada, nadie, op. cit., p. 68)

$\mathrm{Al}$ igual como sucede en otras de sus crónicas, en este ámbito utópico Poniatowska nos muestra a los mexicanos más desprotegidos, a «los nacos... pobres, morenos, indígenas, fracasados, ignorantes, vulgares, vagos» como «la verdadera riqueza de este país» (Poniatowska, Amanecer, op. cit., p. 40), en contraposición a «los valores de los rich and beautiful [que] tienen más que ver con lo imaginario, el poder social, el orgullo, la fama, el prestigio, la apariencia de justicia, la mentira, la guerra, la opinión pública, la ideología» (Ibid., p. 45). Aquí los jóvenes y viejos se aleccionan sobre su presente viendo películas sobre la Revolución Mexicana o documentales sobre la noche de Tlatelolco. Están en este centro porque cifran sus esperanzas en los discursos de un líder que desde su templete los llena de un orgullo pasajero: «Ya quisieran los de arriba ser como los de abajo. ¡Arriba los de abajo!» (Ibid., p. 103). Como si de pronto se hubiera presentado en el Zócalo la Revolución Mexicana, aquí también se dan encuentro «los que llegaron del norte, los que vinieron del sur» (Ibid., p. 123), esta vez para acatar las consignas de Jesusa Rodríguez, soldadera de pelo negro recogido, de huipil y aretes de cuentas huicholes que «oficia misa al aire libre mientras el cardenal Norberto Rivera lo hace entre los gruesos muros coloniales» (Ibid., p. 72). Lo malo de este ambiente de suspensión temporal, tanto real como ideal, de todo rango jerárquico es que propicia un tipo especial de comunicación que sería imposible en la vida cotidiana (Bahktin, op. cit., p. 10). Es una bella ilusión, «una segunda vida» o un «segundo mundo hecho de cultura popular» (Ibíd., p. 11), que irrevocablemente se desintegra apenas se desmontan las carpas del plantón.

Puesta en perspectiva, la crónica de estos cincuenta días es, de alguna manera, la de una muerte anunciada: los que apoyan a AMLO terminan con las manos vacías; Jesusa Rodríguez revela su poca paciencia para atender asuntos que no tengan que ver con la causa política de AMLO; se pierden entre el viento y la lluvia los discursos para combatir la pobre-

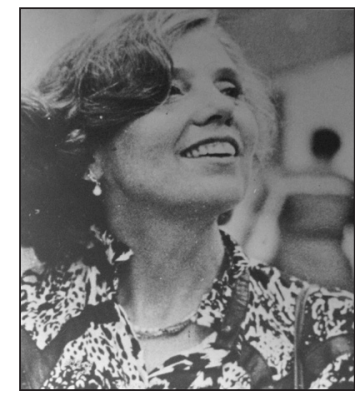

35

Mikhail Bakhtin, Rabelais and His World, trans. Hélène Iswolsky, Bloomington \& Indianapolis, Indiana UP, 1984, p. 9

Ciclos represivos y conflictos de identidad en las crónicas de Elena Poniatowska

OSWALDO ESTRADA 
Hugo Francisco Bauzá, El mito del héroe. Morfología y semántica de la figura heroica, Buenos Aires, Fondo de Cultura Económica, 2007, p. 161

37

Gabriel Weisz, Tinta de exotismo. Literatura de la otredad, México, Fondo de Cultura Económica, 2007, p. 36

38

Linda Egan, "Play on Words: Chronicling the Essay», en Ignacio Corona \& Beth E. Jörgensen (eds.), op. cit., pp. 15-116.

Ciclos represivos y conflictos de identidad en las crónicas de Elena Poniatowska

OSWALDO ESTRADA za y la monstruosa desigualdad, para defender el patrimonio nacional o para enfrentar a la corrupción y la impunidad. En medio de este drama, el «pseudo-héroe» mítico/político ${ }^{36}$ encarnado en AMLO también se desmorona con la misma suerte volteada que Bernal Díaz le atribuye a su héroe Hernán Cortés. Hasta la propia cronista descubre que «la política es una maraña de componendas, argucias, egoísmos, voracidad, que nada es como se dice» (Poniatowska, Amanecer, op. cit., p. 391). Si es cierto, como ella sostiene, que «la cultura se va transformando a lo largo del tiempo, cada siglo le da su sello particular, cada ser humano la interpreta a su modo» (Ibíd., p. 143), su interpretación nos presenta la identidad mexicana atada de manos al pasado. Ante la situación alarmante del país, Poniatowska vuelve a reflexionar: «no estamos lejos de los murales de Orozco en que la justicia con los ojos vendados y borracha levantaba sus balanzas chuecas» (Ibíd., p. 266); distingue a los mexicanos de los estadounidenses por su culto ciego a la Virgen de Guadalupe; habla de la opresión social expuesta por Simone Weil; y confirma que México es un país dividido, clasista, lleno de odio y desigualdad. Uniendo de nueva cuenta el presente al pasado mexicano, Poniatowska resume esta imagen desastrosa, diciendo: «PPobrecito de mi México, víctima primero del gordo cacique de Zempoala y después de la Colonia! ¿Sólo nos ha ido medio bien a partir de la Revolución Mexicana? Claro que no. Todavía hoy no reconocemos el valor de cada hombre sobre la tierra» (Ibíd., p. 329).

El reconocimiento de esta «inestabilidad» social ilumina, valga el aclaratorio, la otredad oculta de la identidad mexicana con cierto matiz de «exotismo» ficcional ${ }^{37}$. Incluso cuando los textos de Poniatowska contienen, como toda crónica actual de México, un mensaje crítico, psicosocial, político, reformista, didáctico y analítico ${ }^{38}$, éste nos interna en un ambiente mítico que pretende «dar respuesta a los grandes interrogantes del género humano -el origen del mundo, lo contradictorio de la naturaleza del hombre, el misterio de la muerte...-, frente a los que el pensamiento racional no ofrece respuestas» (Bauzá, op. cit., p. 157). Si en La noche de Tlatelolco México se convierte en un panteón, tanto que la cronista señala: «Por ahora la sangre ha vuelvo al lugar de su quietud. Más tarde brotarán las flores entre las ruinas y entre los sepulcros» (Poniatowska, Tlatelolco, op. cit., p. 171), después de tres décadas muy poco ha cambiado en
Amanecer en el Zócalo. Como si la existencia de los mexicanos hubiese sido un largo día de fiesta carnavalesca, la cronista imagina con optimismo de ultratumba:

Todos nos volvimos volcanes. Alteramos el paisaje, lo cambiamos irrevocablemente, ahora somos nosotros el terremoto de 1985, somos los mismos que salimos de los escombros, los mismos que tocamos en las campanas de Catedral la muerte del PRI, su paternalismo, su autoritarismo, su corrupción rampante, los mismos que en 1988 toleramos que nos robaran la elección. (Poniatowska, Amanecer, op. cit., p. 392)

Sólo que entre líneas aquí también volvemos a escuchar las voces de Nada, nadie. Los viejos lamentos «yo ya no soy nadie» (Poniatowska, Nada, nadie, op. cit., p. 18), «no quedó nadita» (Ibid., p. 21), «no es nada m'hijo, no es nada» (Ibíd., p. 23) y "yo no tengo a nadie» (Ibid., p. 51), ahora se apoderan del Zócalo, esa "plaza [que] ha vuelto al lugar de su quietud como dice la filosofía náhuatl,» el lugar donde aun «rezumban» y «palpitan todavía las palabras del desafuero» y el deseo de «luchar contra el atropello» (Poniatowska, Amanecer, op. cit., p. 392).

Aun tomando en cuenta la distancia histórica y temporal que a una misma vez hermana y separa a las crónicas de Poniatowska, el que todas ellas en mayor o menor grado demuestren el despertar de una sociedad civil que se organiza, o el que la del 2006 se muestre mucho más cerca a la democracia que la de 1968, todas en conjunto nos entregan a un México hecho de murmullos, de vivos y muertos, de tiempos remotos y tiempos presentes. En total consonancia con la visión mexicana que nos presenta Juan Rulfo en Pedro Páramo (1955), en el mural cronístico de Poniatowska conviven con armonía activistas como la popular Tita del 68, una Evangelina Corona del 85 y una Jesusa Rodríguez del 2006; diosas como la Coyolxauhqui y mujeres escritoras, como Rosario Castellanos que se indigna ante las pérdidas humanas del Movimiento Estudiantil; los políticos como Díaz Ordaz y Vicente Fox, Cárdenas, Andrés Manuel López Obrador, o el Innombrable: Felipe Calderón; los nacos y los catrines; La Revolución Mexicana y las prometedoras Convenciones Nacionales Democráticas, donde lo menos que hay es el diálogo. Vistas desde el presente, y a pesar de su marcado esfuerzo por avanzar hacia la democracia, las crónicas de Poniatowska nos internan en un México 
como aquél concebido por Rulfo: «lleno de ecos...risas. Unas ya cansadas de reír. Y voces desgastadas por el uso,» un tiempo-espacio donde el «mitote» se vuelve "Nada. Nadie» (101) o donde algún muerto grita: «iAy vida, no me mereces!» (93).

La exposición de estas ideas en las crónicas de Elena Poniatowska, como su estudio en el presente ensayo, tiene mucho que ver con los debates actuales sobre la cultura latinoamericana. Hasta cierto punto es cierta la inestabilidad de una cultura, el hecho de que su contenido auténtico no sea más que un mito que pronto se desintegra cuando una expresión cultural se enfrenta con otra ${ }^{39}$. Sea cual fuera nuestra cultura de origen, con pocas excepciones existimos en espacios intermedios, de contacto, razón por la cual es necesario anular cualquier propuesta esencialista sobre la «autenticidad inherente» o la «pureza de las culturas» ${ }^{40}$. Edward Said reconoció este flujo de influencias culturales, señalando: "partly because of empire, all cultures are involved in one another; none is single and pure, all are hybrid, heterogeneous, extraordinarily differentiated, and unmonolithic» ${ }^{41}$. Pese al inevitable estado de hibridación, éste no siempre significa «la fusión, la cohesión, la osmosis, sino la confrontación y el diálogo» ${ }^{42}$. Este enfrentamiento de perspectivas también aparece en los escritos de Poniatowska. Es ahí donde yacen intactas distintas cuestiones, en conflicto, de una fragmentada identidad mexicana de múltiples valores, usos y costumbres, pendiente de alcanzar la igualdad y la justicia social.

\section{OBRAS CITADAS}

Fernando Aínsa, Identidad cultural de Iberoamérica en su narrativa, Madrid, Gredos, 1986.

Esteban Ascencio, Me lo dijo Elena Poniatowska. Su vida, obra y pasiones, contadas por ella misma..., México, Ediciones del Milenio, 1997.

Mikhail Bakhtin, Rabelais and His World, trans. Hélène Iswolsky, Bloomington \& Indianapolis, Indiana UP, 1984.

Roger Bartra, La jaula de la melancolía. Identidad y metamorfosis del mexicano, México, Debolsillo, 2006.

Hugo Francisco Bauzá, El mito del héroe. Morfología y semántica de la figura beroica, Buenos Aires, Fondo de Cultura Económica, 2007.
Rosa Beltrán, «Elena Poniatowska. Literatura y periodismo», Revista de la Universidad de México, 51 (2008), pp. 8-12.

Anadeli Bencomo, Voces y voceros de la megalópolis. La crónica periodístico-literaria en México, Madrid, Iberoamericana / Vervuert, 2002.

Homi K. Bhabha, The Location of Culture, London \& New York, Routledge, 1994.

Claire Brewster, Responding to Crisis in Contemporary Mexico. The Polical Writings of Paz, Fuentes, Monsiváis, and Poniatowska, Tucson, U of Arizona P, 2005.

Elizabeth Coonrod Martínez, «Elena Poniatowska: Between the Lines of the Forgotten», Américas, 57:2 (2005), pp. 46-51.

Denise Dresser, «Elena Poniatowska: soldadera de lo nuestro", Revista de la Universidad de México, 39 (2007), pp. 18-21.

Bolívar Echeverría, Vuelta de siglo, México, Era, 2006.

Linda Egan, Carlos Monsiváis. Culture and Chronicle in Contemporary Mexico, Tucson, U of Arizona P, 2001.

- «Play on Words: Chronicling the Essay», en Ignacio Corona \& Beth E. Jörgensen (eds.), The Contemporary Mexican Chronicle. Theoretical Perspectives on the Liminal Genre, Albany, State U of New York P, 2002, pp. 95-122.

Enrique Florescano, (ed.), Mitos mexicanos, México, Aguilar, 1995.

Néstor García Canclini, Culturas híbridas. Estrategias para entrar y salir de la modernidad, México, Grijalbo, 2001.

- La globalización imaginada, Buenos Aires, Paidós, 2005.

Margarita García Flores, «Entrevista a Elena Poniatowska», Revista de la Universidad de México, 30:7 (1976), pp. 25-30.

Todd Gitlin, «The Cant of Identity», in Daphne Patai \& Will H. Corral (eds.), Theory's Empire. An Anthology of Dissent, New York, Columbia UP, 2005, pp. 400-411.

Beth E. Jörgensen, «Actos de atención: intersecciones en el pensamiento social de Weil, Castellanos y Poniatowska», Revista Canadiense de Estudios Hispánicos, 31:3 (2007), pp. 413-29.

- «Matters of Fact: The Contemporary Mexican Chronicle and/as Nonfiction Narrative», en Ignacio Corona \& Beth E. Jörgensen (eds.), The Contemporary Mexican Chronicle. Theoretical Perspectives on the Liminal Genre, Albany, State U of New York P, 2002, pp. 71-94.
Neil Larsen, Determinations. Es says on Theory, Narrative, and Nation in the Americas, London \& New York, Verso, 2001, p 91 .

40

Homi K. Bhabha, The Location of Culture, London \& New York Routledge, 1994, p. 58, la traducción es mía.

41

Edward W. Said, Culture and Imperialism, New York, Alfred A. Knopf, 1993, p. xxv.

42

Néstor García Canclini, Culturas híbridas. Estrategias para entrar y salir de la modernidad, México, Grijalbo, 2001, p. ix.

Ciclos represivos y conflictos de identidad en las crónicas de Elena Poniatowska

OSWALDO ESTRADA 
- The Writing of Elena Poniatowska: Engaging Dialogues, Austin, U of Texas P, 1994.

Enrique Krauze, La presencia del pasado, México, Tusquets, 2005.

Jorge Larrain, Identity and Modernity in Latin America, Oxford, Polity, 2000.

Neil Larsen, Determinations. Essays on Theo$r y$, Narrative, and Nation in the Americas, London \& New York, Verso, 2001.

Carlos Monsiváis, "On the Chronicle in Mexico», trans. Beth E. Jörgensen, in Ignacio Corona \& Beth E. Jörgensen (eds.), The Contemporary Mexican Chronicle. Theoretical Perspectives on the Liminal Genre, Albany, State U of New York P, 2002, pp. 25-45.

Herminio Núñez Villavicencio, «Sobre el concepto de identidad latinoamericana», Cuadernos Americanos, 124 (2008), pp. 181-99.

Rocío Oviedo Pérez de Tudela, «Palabra y tierra: entrevista a Elena Poniatowska», Anales de Literatura Hispanoamericana, 30 (2001), pp. 341-58.

Octavio Paz, Tiempo nublado, Barcelona, Seix-Barral, 1983.

Elena Poniatowska, Amanecer en el Zócalo, México, Planeta, 2007.

- «A Question Mark Engraved on My Eyelids», Trans. Cynthia Steele, en Margaret Sayers Peden (ed.), Mexican Writers on Writing, San Antonio, Texas, Trinity UP, 2007, pp. 96-109.

- «How I Started Writing Chronicles and Why I Never Stopped», trans. Beth E. Jör- gensen, en Ignacio Corona \& Beth E. Jörgensen (eds.), The Contemporary Mexican Chronicle. Theoretical Perspectives on the Liminal Genre, Albany, State U of New York P, 2002, 37-45.

- La noche de Tlatelolco, México, Era [1971], 2001.

- Luz y luna. Las lunitas, México, Era, 1994.

- Nada, nadie. Las voces del temblor, México, Era, 1988.

- Todo empezó el domingo, México, Océano [1963], 1997.

Sara Poot Herrera, «Las crónicas de Elena Poniatowska», Colmena, 11 (1996), pp. 17-22.

Susana Rotker, La invención de la crónica, México, Fondo de Cultura Económica/ Fundación para un Nuevo Periodismo Iberoamericano, 2005.

Edward W. Said, Culture and Imperialism, New York, Alfred A. Knopf, 1993.

Juan Rulfo, Pedro Páramo, José Carlos González Boixo (ed.), Madrid, Cátedra, 2003.

Vivian Schelling, "Popular Culture in Latin America», in The Cambridge Companion to Modern Latin American Culture, John King (ed.), Cambridge, Cambridge UP, 2004, pp. 171-201.

Michael K. Schuessler, Elenisima. Ingenio y figura de Elena Poniatowska, México, Diana, 2003.

Gabriel Weisz, Tinta de exotismo. Literatura de la otredad, México, Fondo de Cultura Económica, 2007.
Ciclos represivos y conflictos de identidad en las crónicas de Elena Poniatowska

OSWALDO ESTRADA 